\title{
MADRES Y MADRASTRAS: MODELOS DE GÉNERO, HETERODESIGNACIÓN Y FAMILIAS RECONSTITUIDAS
}

\author{
BEATRIZ MONCÓ \\ Universidad Complutense de Madrid
}

Recibido: $24 / 03 / 2014$

Aceptado: 12/05/2014

\section{Resumen}

Maternidad y familia ha sido un tema importante para la teoría y la crítica feminista. Igualmente el feminismo se ha interesado por las denominadas «nuevas familias»y el papel que cumplían en el orden social. Las familias reconstituidas forman parte de este grupo y son actualmente la estructura familiar de muchas mujeres y el escenario de representación de modelos de género y asignaciones patriarcales. En este texto se analizan, desde la antropología del género, las permanencias y los cambios que subyacen a este tipo familiar así como a las figuras femeninas de las madres y madrastras. Al tiempo, se realiza una mirada crítica a un modelo maternal que impide la libertad femenina y establece norma exclusiva para las mujeres.

Palabras clave: Madre, madrastra, heterodesignación, familia, antropología de género.

\begin{abstract}
Motherhood and family has been a major topic for feminist theory and critique. Also, feminism has been interested in the so-called «new families» and the role they played in the social order. Reconstituted families are part of this group and the family structure of many women currently. They are also the model representation of gender and patriarchal assignments. From an anthropology of gender point of view, this text analyses the changes that underlie this family type, as well as mother and stepmother female figures. At the same time, the text takes a critical look at a model that prevents women's freedom and establishes exclusionary rule for them.
\end{abstract}

Keywords: mother, stepmother, heterodesignation, family, gender anthropology. 



\section{Introducción}

Desde los inicios de la Antropología Social los denominados «sistemas de parentesco y familia» constituyeron un foco central de interés de la disciplina. Bajo este ámbito las mujeres fueron objeto de atención como madres, hijas y hermanas de hombres que habitualmente eran los verdaderos protagonistas de las etnografías más clásicas. Esta situación, común en la mayor parte de los trabajos antropológicos de finales del XIX y principios del XX11, comenzó a transformarse en la década de los setenta, con la llamada «antropología de la mujer» para variar completamente en los ochenta con el surgimiento claro de la antropología del género que aquí entendemos como feminista. Algunas de las investigaciones de estos primeros años giraron igualmente alrededor de la familia, pero con un énfasis analítico de los sistemas de dominaciónsubordinación de hombres y de mujeres, las causas que podrían motivarlos y, al menos en cierta medida, interrogándose sobre el significado que el matrimonio (como parte clave del contrato sexual) y sobre todo la maternidad tenían para las mujeres.

En este sentido debemos recordar que desde 1949 y la aparición de El segundo sexo de Simone de Beauvoir buena parte de las reflexiones feministas pusieron de relieve que la maternidad y las funciones que lleva aparejadas (tanto físicas, como socioculturales e incluso simbólicas) impedían una posición social de prestigio para las mujeres, a pesar de que en algunas sociedades estudiadas por antropólogos y antropólogas los datos etnográficos confirmasen que, con el transcurso del tiempo, el prestigio de una mujer se mediría por la importancia y el status de sus hijos varones. De uno u otro modo para la autora francesa estaba claro que la maternidad no sólo no era beneficiosa para las mujeres sino que, además, este hecho la perjudicaba a la hora de

1. La antropología del género ha recuperado un conjunto de nombres femeninos y de obras etnográficas que pueden considerarse precursoras de este ámbito de estudio. Puede verse al respecto las obras de MARTín CASARES, Aurelia. Antropología del género. Culturas mitos y estereotipos sexuales. Madrid, Cátedra, 2006; MÉNDEZ, Lourdes. Antropología feminista. Madrid, Editorial Síntesis, 2007 y MONCÓ, Beatriz. Antropología del género. Madrid, Editorial Síntesis, 2011. 
ser considerada socialmente como un sujeto pleno, un individuo total, un ser trascendente $e^{2}$. De ahí, que algunas autoras norteamericanas herederas de Beauvoir, desde perspectivas propias del feminismo radical, no vieran en la maternidad más que una forma de apropiación patriarcal de los cuerpos de la mujeres y propusieran soluciones drásticas mediante, por ejemplo, la sustitución de la gestación por técnicas de reproducción asistida ${ }^{3}$, un hecho curioso si pensamos en lo polémicas que son hoy día las TRA para algunas opiniones feministas. Por la década de los setenta también, desde lo que luego sería la antropología del género, surgieron dos planteamientos teóricos de importancia que trataron de explicar, desde perspectivas universalistas, la posición de subordinación que las mujeres tienen en todas las sociedades. Sherry Ortner vería que la única causa de tal estado de cosas sería la dicotomía valorativa, representativa y simbólica que produce homologar a los hombres con la cultura y a la mujer con la naturaleza mientras que Michelle Rosaldo lo explicaría mediante la unión de la mujer a la esfera de lo doméstico y el hombre a la de lo público. Independientemente de los problemas teóricos y metodológicos que conllevan estas dos teorías lo cierto es que de nuevo parecía vincularse la dominación de las mujeres con la familia, la maternidad y el cuidado de los hijos, un aspecto que encontraría también perfecto acomodo en los posteriores planteamientos de cierta tradición feminista francesa (Marie-Blanche Tahon, Françoise Héritier o Nicole Mathieu) y en las perspectivas marxistas de Eleanor Leacock e incluso Claude Meillasoux ${ }^{4}$.

Hay que recordar también que en la década de los setenta Adrienne Rich publicaría Of Woman Born ${ }^{5}$, un texto paradigmático de otro modo feminista de mirar y analizar la maternidad. En su opinión la clave estaría en distinguir entre la maternidad-institución (es decir, un conjunto de deberes, leyes, costumbres, recetas, representaciones colectivas y exigencias sociales que conforman un modelo normativo por el que estamos bajo el control masculino) y maternidad-experiencia, que bascularía, tal y como titula el primer capítulo,

2. Pueden rastrearse sus opiniones, referidas esta vez a su propia madre y a su relación particular, en Une morte très douce. Paris, Gallimard, 1964.

3. Esta es la propuesta, evidentemente muy resumida, que realizada Shulamith Firestone en La dialéctica del sexo. Barcelona, Kairós, 1976.

4. Puede verse una ampliación de algunas de estas autoras en los libros mencionados de Martín Casares, Méndez y Moncó y en IMAZ, Elixabete. Convertirse en madre. Etnografía de la gestación. Madrid, Cátedra, 2010.

5. Of Woman Born. Motherhood as Experience and Institution se publicó por primera vez en 1976, haciéndose una segunda edición en 1986 con un nuevo prólogo de la autora. Esta es la edición que se tradujo al castellano con el título de Nacemos de mujer. La maternidad como experiencia e institución. Madrid, Cátedra, 1996. 
entre la cólera y la ternura. Es importante señalar aquí que para esta autora la consideración de que la maternidad enajena a la mujer es un resultado de premisas que derivan, precisamente, del orden social que el feminismo combate. De ahí que, como experiencia femenina, la plantee como una opción, una potencialidad e incluso como una fuente de placer y poder femenino que empieza por la recuperación del propio cuerpo, abriendo así la puerta a otras consideraciones de la maternidad y su vivencia tales como las de Sara Ruddick, Yvonne Knibiehler ${ }^{6}$ y las propias del feminismo maternal ${ }^{7}$, de feministas de la diferencia y ecofeministas.

Además, tal y como demostraban sobradamente los datos etnográficos de varias antropólogas así como los trabajos de investigación de las historiadoras y sociólogas del género feministas, los requerimientos de la maternidad, con diferencias de carácter histórico-cultural evidentemente ${ }^{8}$, habían influido en las mujeres y sus posiciones en todos los lugares y todas las épocas. Parecía, pues, que habría que esperar a momentos históricos más benevolentes con las mujeres, a sociedades con amplios márgenes de desarrollo que permitiesen su presencia y relevancia en lo público y a sistemas familiares en los que el

6. Sara Ruddick equipara los cuidados maternales a una política de pacifismo, mientras que Yvonne Knibiehler interpreta el feminismo como un humanismo y la maternidad como un recurso político mediante el que influir en el desarrollo de la ciudadanía y sus derechos.

7. Llamado también maternalista (Seth Coven y Sonya Michel), familiar o familiarista y más tarde relacional (Karen Offen). Podría decirse que este feminismo y sus militantes luchan por el reconocimiento de la actividad maternal como un trabajo que, como cualquiera de ellos, debe ser reconocido socialmente y económicamente. Véase el texto de TOuPIN, Louise. «Des usages de la maternité en histoire du féminisme». Recherches féministes 9, no 2 (1996), pp. 113-135. Defensoras muy actuales y conocidas del maternalismo son, entre otras, Sylviane Agacinski, Antoinette Fouqué o la norteamericana Sarah Blaffer Hrdy,para quien el instinto materno en mujeres es semejante al del resto de animales mamíferos. No hay que olvidar que es sociobióloga y primatóloga aunque es cierto que sus opiniones están teniendo gran relevancia para algunos grupos femeninos. Es interesante al respecto ver la crítica de BADINTER, Elisabeth. Por el mal camino. Madrid, Alianza Editorial, 2004 y, matizando la perspectiva de este texto (editado originalmente en el 2003 con el título de Fausse route) es interesante La mujer y la madre. Madrid, La esfera de los libros, 2011. Es evidente que Badinter continúa en la línea deconstructiva del modelo dominante de maternidad abierto con L'amour en plus. Histoire de l'amour maternel, Paris, Flammarion, 1980 cuya traducción se cita en la bibliografía.

8. Las referencias bibliográficas son numerosísimas a este respecto, pero destaco aquí algunas que me han sido muy sugerentes dentro de una perspectiva histórica. KNIBIELHER, Yvonne. Historia de las madres y de la maternidad en occidente. Buenos Aires, Nueva Visión, 2001; CID LÓPEZ, Rosa María (Ed.). Maternidad/es: representaciones y realidad social. Edades Antigua y Media. Madrid, Al-Mudayna, 2010 y FrANCO RUBIO, Gloria A. (Ed.). Debates sobre la maternidad desde una perspectiva histórica (siglos XVI-XX). Barcelona, Icaria Editorial, 2010.

Feminismo/s 23, junio 2014, pp. 113-133 
contrato matrimonial y la división sexual del trabajo les permitieran mayor autonomía y posibilidades. Es en este sentido que considero de gran importancia la crítica feminista a la unicidad de la familia así como el respaldo e impulso que han tenido desde ella las denominadas «nuevas familias»?.

\section{Las «nuevas familias»}

Tal y como algunos autores ${ }^{10}$ habían previsto, uno de los aspectos de cambio más llamativos en el sistema familiar de la llamada sociedad occidental es el pluralismo de las formas familiares. Una variedad, por otra parte, que se inserta dentro de un conjunto de transformaciones de diverso calado que son la señal visible de buena parte de las luchas de los movimientos sociales y evidentemente del feminismo: libertad de escoger la vida que consideramos oportuna y exigencia de respeto e igualdad a la diversidad de las opciones de cada persona en su vida privada y afectivo-sexual. Por otra parte, signo de la nueva modernidad, es la individualización creciente que convierte los esquemas rígidos existenciales de hace unas décadas en trayectorias vitales abiertas y flexibles donde las elecciones personales juegan un papel principal. Preferencias que además pueden resultar en extremo paradójicas al tratar de combinar necesidades afectivas y familiares con la defensa de la propia individualidad y autonomía.

Por otra parte, es necesario no olvidar que las formas familiares y los mismos individuos, así como las transformaciones sufridas por unas y otros, acontecen en unos contextos económicos y sociales determinados. Es decir, cualquier tipo familiar es también un reflejo de una estructura social y política singular; de hecho conocemos perfectamente que en la organización económica de fuerte liberalidad de mercado, con una estructura flexible de producción, se requieren sujetos con altos índices de individualización, hombres y mujeres sin ataduras, trabajadores y trabajadoras «setas», sin raíces ni compromisos. Todo ello, evidentemente, encaja mal con proyectos vitales afectivos y familiares a medio y largo plazo así como con cualquier planificación futura que requiera un mínimo de certidumbre. Igualmente hay que tener presente que la familia nuclear fue respuesta adecuada a las exigencias de un momento histórico y cultural concreto y que a su vez se combinó y coexistió

9. AlBERDI, Inés. «La transformación de las familias en España. La influencia del feminismo en los cambios familiares». Arxius de sociología, 15 (2006), pp. 25-40

10. BAumAn, Zigmunt. Amor líquido. Acerca de la fragilidad de los vínculos humanos. Madrid, FCE, 2005. y BECK, Ulrich y BECK-GERNSHEIM, Elisabeth. La individualización. El individualismo institucionalizado y sus consecuencias sociales y políticas. Barcelona, Paidós, 2003. 
desde su origen con otras pautas familiares ${ }^{11}$. Resultan curiosos, pues, los lamentos por la existencia de «otras» familias sin tener en cuenta que, en cierta medida, la familia nuclear, nuestro modelo por excelencia, fue en algún momento histórico determinado «otra» familia también. Hoy día sin embargo la familia nuclear es un modelo familiar mayoritario pero en declive en el mundo occidental que está dando paso a otros modos de vivir en familia. La transformación, además, no sólo es una cuestión de estructuras, sino de cambios más profundos que afectan a representaciones colectivas, valores, formas de pensamiento y lenguaje y deseos personales.

Por otra parte, transformaciones demográficas, económicas, laborales, valorativas y culturales, han generado modificaciones en las prácticas familiares y en sus representaciones suponiendo rupturas mentales y conceptuales que obligan a los individuos a repensar su familia y a repensarse a sí mismos a partir de otras realidades y otras lógicas. Así, hoy separamos hogar y familia con el caso de las recompuestas o las parejas L.A.T (acrónimo de living apart together) que aún teniendo una relación de pareja deciden vivir separadas ${ }^{12}$, también contamos con la posibilidad de establecer lazos de filiación de forma independiente a los conyugales o de pareja, como por ejemplo las solteras que adoptan a un hijo o una hija ${ }^{13}$ o se someten a TRA o con la disyunción de reproducción y sexualidad como vemos con este último caso o la llamada maternidad subrogada. Podríamos además apuntar que hoy día lo genético, lo biológico y lo social son ámbitos diferentes que pueden dar lugar a paternidades y maternidades distintas; así una persona puede tener una madre social que puede ser o no genética y que puede o no coincidir con la biológica. Y en otro sentido podemos hablar también de familias biparentales, homoparentales y homomarentales, monoparentales y monomarentales, transnacionales e incluso de coparentalidad. Es claro también que actualmente existe una

11. FlandRin, Jean Louis. Orígenes de la familia moderna. La familia, el parentesco y la sexualidad en la sociedad tradicional. Barcelona, Crítica, 1979.

12. Ver AYUSO, Luis. "Living apart together en España ¿Noviazgo o parejas independientes». RIS $70 n^{\circ} 3$ (2012), pp.587-613. En mi opinión un hogar forman las denominadas nuevas formas de convivencia (algunos autores incluyen en el concepto a los L.A.T.) como por ejemplo las denominadas Just Woman una opción en la que algunas mujeres deciden vivir con amigas independientemente de su vida familiar, es decir, que muchas de ellas pueden tener hijos y pareja pero no conviven con ellos.

13. Sabemos que la adopción de niños y niñas ha existido a lo largo de toda la historia, en diversos grados y con diferentes nombres, aunque casi siempre era por existencia de una relación (familiar o no) anterior a este hecho. Sin embargo los procesos de adopción internacional son actuales, así como el que lo realicen las mujeres en solitario, voluntaria y libremente. Son igualmente novedosas las maternidades y/paternidades mediante TRA. 
separación clara entre las relaciones conyugales y las relaciones filiales. Si habitualmente en una familia el esposo y la esposa (pareja conyugal) coincidían con el padre y la madre, es decir, con la pareja reproductora (padres genéticos y biológicos) y con los padres sociales (pareja parental), hoy día unos y otros pueden o no coincidir. Este es el caso, precisamente, de las familias reconstituidas ${ }^{14}$ que veremos a continuación.

\section{Las familias recompuestas}

Siempre me ha llamado la atención el hecho de que estas familias entraran dentro del concepto más amplio de «nuevas familias», sobre todo porque a través de la historia y la literatura puede comprobarse que este tipo familiar ha existido en todas las épocas dado que ha sido muy común, por diversas causas, los matrimonios entre personas viudas (hombre o mujer o ambos) que aportaban hijos e hijas a un segundo matrimonio y que convivían con ellos y ellas y junto a los que pudieran tener con su nuevo esposo o esposa. Hemos de pensar pues, que la novedad de este tipo familiar reside en el hecho de que en la actualidad buena parte de las familias recompuestas se generan tras un divorcio y no por fallecimiento de uno de los miembros de la pareja anterior. Esto, como veremos, tiene una gran importancia a la hora de visionar una familia de este tipo, ya que están presentes tanto los miembros de la o de las parejas conyugales anteriores al mismo tiempo que los correspondientes a la pareja actual, dándose así el caso de varias recompuestas enlazadas en una cadena sucesiva de familias de este tipo. Dicho de otra manera, si anteriormente una persona de familia recompuesta partiendo de viudez se encontraba viviendo, por ejemplo, con un padrastro, un hermanastro, un medio hermano y su madre, ahora ese mismo sujeto podría tener también y al tiempo, un padre, una hermanastra, una media hermana y una madrastra ${ }^{15}$ aunque no conviviera con ellos habitualmente. Esta posibilidad de integrar miembros nuevos de esta familia y aquellos que provienen de otra ha influido en su nominación: familias reconstruidas, recompuestas, reconstituidas, mixtas, e

14. A lo largo del texto me voy a referir sólo a reconstituidas heterosexuales. Las familias homoparentales y homomarentales pueden ser también reconstituidas, proviniendo los hijos o hijas de una relación heterosexual dentro de familias nucleares e inclusive también recompuestas. En el caso de las familias homomarentales dos figuras maternas pueden combinarse con una tercera o incluso una cuarta (la pareja del padre, anterior pareja de una de los miembros de la homomarental o ser este el caso de las dos).

15. Para mayor ampliación de uso y significado de estas nomenclaturas de parentesco puede verse MONCÓ, Beatriz y RIVAS, Ana María. "La importancia de nombrar. El uso de la terminología de parentesco en las familias reconstituidas». Gazeta de Antropología (2007) 
incluso puzles ${ }^{16}$; nombres, todos ellos, que parecen recordar que algo se ha roto y se ha vuelto a rehacer ${ }^{17}$. Siguiendo sin embargo con la tradición académica estas familias se consideran nuevas formulaciones, nuevos tipos que, como decía anteriormente, responden a cambios importantes ocurridos no sólo en la institución matrimonial en sí sino en el marco formal de un grupo social, en las representaciones colectivas y en los valores de los individuos. No obstante, también es cierto que si tomásemos sincrónicamente una de estas familias que no tiene convivencia continuada porque el padre o la madre no tienen la custodia del hijo o hija, parecerían típicas familias nucleares a un punto tal que los propios actores así pudieran creerlo:

Me hace mucha gracia cuando pienso que ahora mi familia sería de ese tipo. Yo, para mí, mi familia era como todas las de las demás niñas [...] mi padre, mi madre y sí, mi hermana Patro que de verdad no era hija de mi padre y mi hermano Tomás y mi hermana María que no lo eran de mi madre, pero no sé, yo tenía tres hermanos, vivíamos allí (juntos), mi padre, mi madre [...] como todo hijo de vecino. Y todos igual, yo nunca he oído nada diferente en el pueblo, que nos llamaran, ni nada de eso $^{18}$ (Leticia)

Las percepciones, pues, de los individuos se construyen a veces de acuerdo a una terminología que no es la académica, que no es la correcta y que incluso aparece modificada según sentimientos, emociones, vivencias y experiencias de los sujetos. Es importante, pues, establecer que la imagen de las familias recompuestas cambia según se privilegien los análisis de determinados componentes (la residencia, la posición de los hijos e hijas respecto a sus grupos de filiación, la custodia y sus tipos, etc.) siendo también interesante el hecho de analizar los usos estratégicos que cada familia hace de todo o parte de ello y que sin duda ofrece una variedad de casos y situaciones a tener en cuenta

16. Incluso han sido denominadas «familias sin nombre» por Pierre Bourdieu en su texto «Des familles sans nom», Actes de la recherche en Sciences Sociales $113 n^{\circ} 1$ (1996), pp. 3-5.

17. Irene Théry escribió un artículo sobre estas familias titulado «Remariage et familles composées: des evidences aux incertitudes». L' Année Sociologique 37 (1987), pp. 119152 en el que abogaba por romper con esa idea de tomar como referencia la familia nuclear arguyendo que si bien podría ser cierto en el caso histórico de recomposición por fallecimiento en este tipo de familia sigue existiendo un padre o una madre que puede querer seguir ejerciendo como tal, lo que para ella la constituye como un tipo familiar diferente.

18. Las citas corresponden a entrevistas tanto a un trabajo que realicé junto a otros compañeros y compañeras en el 2005, subvencionado por el Ministerio de Trabajo y Asuntos Sociales (Orden TAS 1051/2005) cuya investigadora principal fue A.M. Rivas, como a otras investigaciones propias realizadas en diferentes épocas y lugares y en las que me interesaba por cuestiones sobre género, familia y/o maternidades. En todas las citas se han cambiado los nombres de las personas informantes. 
dado que suponen tácticas familiares muy diferentes a las que pudiera darse en otros tipos de familia.

\section{Madres y madrastras como modelos dicotómicos}

Como se ha podido comprobar con la informante anterior y he tenido ocasión de señalar en otro lugar ${ }^{19}$, al nombrar el mundo tomamos parte de él, se nos hace visible y nos hacemos también visibles, nos incorporamos a la realidad y al tiempo la hacemos nuestra. El hecho de poder distinguir, igual que el querer distinguir, a una persona, un acto, una relación o una situación tiene significado tanto para el actor que diferencia como para la persona o la cosa diferenciada. Hemos visto al principio de este texto que desde posiciones dispares la teoría feminista no ha dejado de llevar su mirada crítica a un modelo cultural de maternidad que ha surgido desde el poder (como todo modelo dominante) con el objetivo de ser único, incontestable, inmodificable y permanente en el tiempo. Un modelo que aúna componentes instintivos, naturales, psicológicos, sociales, simbólicos y culturales; que mezcla sucesos biológicos con sentimientos, emociones, tareas y responsabilidades; que construye una metonimia cultural que confundiendo la parte por el todo homologa madres a mujeres y que, finalmente, adjudica valor y plusvalía simbólica a las personas según los mandatos de género y los procesos de heterodesignación. Un modelo unido por lo general al de familia nuclear.

Además, este modelo de maternidad dominante cumple unas funciones claras que permiten así mismo moralizar a las mujeres y transformarlas en buenas y malas madres a tenor o no del cumplimiento de sus mandatos y, por extensión, a considerar a todas las mujeres sujetos de esta medida valorativa. La buena madre es aquella que, desde un principio, se siente atraída por su hijo o hija, que los ama irremediablemente y para siempre, que los cuida y protege, que sacrifica su tiempo, su energía, sus proyectos y hasta su vida por él o ella y que, finalmente, hace de la abnegación una seña de identidad, el único modo de ser y estar en la maternidad y en la vida. La mala madre, por el contrario, es egoísta de su tiempo y esfuerzo, de sus cuidados y de su sacrificio; es la madre que no acompaña el total desarrollo de sus hijos, que no permanece de continuo a su lado, que entiende su identidad de mujer como algo diferente y no siempre encajable con la de madre. Este, llamémosle por ahora contra-modelo de maternidad, ha sido ampliamente tratado por parte de algunos filósofos, Rousseau por ejemplo, y más actualmente por el psicoanálisis, especialmente los discípulos de Freud, y como era de esperar ampliamente

19. MONCÓ y RIVAS, op. cit. 
contestado por algunas teóricas feministas como Kate Millet o Betty Friedan ${ }^{20}$. Sin embargo, llama poderosamente la atención que la «mala madre» haya estado escondida en el discurso popular tras la idea de que si algo falla aquí no es el modelo sino la persona, la mujer en concreto, convirtiéndose así la mala madre en un indecible, un impensable personal y colectivo, que subvierte buena parte de los imperativos ideológicos del parentesco.

Respecto a las madrastras vemos que si superamos lo que de ellas dice el Diccionario de la Lengua Española en su primera acepción (mujer del padre respecto a los hijos llevados por éste al matrimonio) todas las demás entradas permiten apreciar que es término despectivo de madre, una cosa que incomoda o daña, cárcel en germanía e incluso conocer algunos que otros refranes que siguen esta línea negativa. De madrastras, además, poco sabemos a través de la Historia sino es su defensa de los hijos propios y sus bienes frente a los que corresponden a los hijastros. De madrastras conocemos también lo que nos dicen los cuentos tradicionales e infantiles ${ }^{21}$ que sin duda alguna han marcado claramente esta figura con tales trazos negativos que sus valores y representaciones culturales han llegado hasta hoy día independientemente de que realmente se puedan encarnar o no en una persona en concreto:

Tuve mala suerte, perder a mi madre y por tener esa madrastra, por las dos cosas. No me pegaba, eso es cierto, pero tampoco me daba cariño o apoyo. Me daba de comer, cuidaba de mi ropa, estaba pendiente del colegio, pero al parecer yo todo lo hacía mal, todo el día regañándome; ya hubiera yo querido perderme en el bosque y que me hubieran encontrado siete enanitos simpáticos y amables, de verdad te lo digo. (Cecilia)

A Rita nunca le puse ese nombre. Sí, ya sé que lo era, así a veces me preguntaban por ella, pero fíjate, hasta me sentaba mal. (¿Por qué te sentaba

20. Millet, Kate. Política Sexual. Madrid, Cátedra, 1995 y FriedAn, Betty. La mística de la feminidad. Madrid, Cátedra, 2009.

21. Personalmente los encuentro un foco de significado cultural de primera línea y un instrumento de primera mano para analizar procesos de educación y socialización además de una herramienta importante para construir y/o reforzar modelos y normativas de género. Esa es la razón de que utilizara este medio para explicar a niños y niñas temas como la igualdad entre hombres y mujeres, la violencia de género y el significado de la ciudadanía (puede verse: MonCó, Beatriz. Mercedes quiere ser bombera (2004); Los hombres no pegan (2005) y Clara y la ciudadanía (2009), todos ellos, de la Editorial Bellaterra, han sido traducidos y publicados en catalán). Varias autoras, desde hace años, están volviendo a interpretar y reescribir cuentos tradicionales bajo otras consideraciones más acordes a las perspectivas feministas y de género. De todos modos, como he dicho, en primeras versiones de cuentos muy conocidos, por ejemplo de La bella durmiente, existen otros personajes femeninos terribles, que son madres pero también suegra o esposa. Los padres también pueden aparecer como seres tremendos y, en ocasiones, poner en verdaderos compromisos a las hijas (por ejemplo en Rumpelstiltskin) o incluso pretender contraer matrimonio con ellas (el caso de Piel de Asno).

Feminismo/s 23, junio 2014, pp. 113-133 
mal?) No sé, no sé decirte... esa palabra, tan fuerte, tan fea ¡quizás me recordaba a las de los cuentos, ya sabes! y yo no era Pulgarcito, ni me abandonaba, ni me mataba de hambre, ni me pegaba, no sé. La verdad es que sería muy injusto para ella, ha sido una buena persona conmigo, me ha cuidado, me ha querido, y yo a ella. Como te digo no es la típica de los cuentos, de verdad, no sería justo, esa palabra dice tanto, no sería justo para ella. (Jorge)

Tanto Cecilia como Jorge, aun con experiencias distintas, encuentran en los cuentos infantiles una clara referencia para su discurso y al mismo tiempo un lugar común para explicarme su situación y sentimientos, un punto que, como así fue, saben que yo voy a entender y significar de igual manera. Los cuentos, ello es evidente, no son toda la realidad, pero sí que muestran una parte de ella y dan pautas para encararla formando parte importante de la educación informal infantil. Es así que un simple recuerdo de cuentos como Blancanieves, Hansel y Gretel o La Cenicienta nos ofrecen elementos constitutivos de la figura y rol de madrastra que abundan en esta imagen negativa de la que vengo hablando. Lógicamente dado el momento de surgimiento de estas historias $^{22}$ (curiosamente llamadas por los Grimm «Cuentos de la infancia y el hogar») en todas ellas la madre del héroe o heroína ha muerto ${ }^{23}$. En todos ellos también encontramos un padre ausente (por viaje o al más puro estilo del padre que desde el feminismo analizó Chodorow ${ }^{24}$ que abandona a sus hijos e hijas en manos de la madrastra. Y también hallamos un conjunto de malos sentimientos que desencadenan la tragedia del cuento. Sin embargo, pensemos en que estas tres madrastras son también diferentes y pueden ser situadas en un continuum que va desde el deseo de muerte y un cuádruple intento de asesinato en Blancanieves ${ }^{25}$ al abandono que sufren Hansel y Gretel en medio del bosque o al fastidio continuo que supone para Cenicienta ser la

22. Me refiero, claro está, a las fuentes escritas, no a la narración popular, anterior y difícil de datar. Charles Perrault, por ejemplo, escribe en el XVII y Jacob y Wilhem Grimm inician sus publicaciones más conocidas sobre 1812-1815. Años después, en 1859, la Condesa de Ségur publicaría Les malheurs de Sophie (Las desgracias de Sofía). Sofía es una niña continuamente reprendida, imprecada y golpeada «jusqu'a ce que ses bras fussent fatigués» por su madrastra Mme. Fichini. (Utilizo una versión de Les petites filles modèles, publicada por Hachette en 1930. La cita corresponde a la página 103).

23. En las versiones orales Hansel y Gretel tenían madre; más tarde este malvado personaje (una «mala madre» en toda regla) se convertiría en una madrastra acorde con el modelo que hablamos. Al final de la historia ella está muerta y así Hansel, Gretel y el padre pueden vivir felices para siempre con la riqueza de la bruja que les había tenido prisioneros.

24. CHODOROW, Nancy. El ejercicio de la maternidad. Barcelona, Gedisa, 1984.

25. Me refiero al cuento popular que más tarde recogieron los hermanos Grimm y que en versiones posteriores se fue modificando y edulcorando. La madrastra, con disfraces diferentes, trata de asesinar a Blancanieves en tres ocasiones (la última con una 
que hace todas las tareas de la casa y además quedar encerrada para el baile. Vistos en secuencia, los cuentos dejan claro los matices de la figura que el modelo no permite ver. La madrastra no es buena, no es el ideal, no es una madre; pero hay un gran espacio para situar sus roles y representaciones a pesar de que culturalmente, al transmitirse los modelos sin modificaciones sustantivas, se haya convertido en la antítesis de la madre y reforzadora del modelo materno.

\section{La conjunción de madres y madrastras en las familias recompuestas}

Como hemos visto con anterioridad lo que singulariza hoy día a las familias recompuestas es la posibilidad de una existencia conjunta de madres y madrastras ${ }^{26}$ en la vida de una persona. Esto origina que un hijo o hija en concreto tenga que convivir habitualmente con una madre y a veces con una madrastra o incluso a partes iguales con ambas si existe custodia compartida tras el divorcio. En realidad en estas familias recompuestas madre y madrastra se construyen y deconstruyen de un modo relacional y al hacerlo los sujetos tienen en cuenta su experiencia con ellas, sus valores y sus interpretaciones (lo que hacían más arriba Jorge y Leticia), además de lo que hacen sus madres, el conjunto de personas que les rodea ${ }^{27}$ y los modelos culturales que les envuelven.

No obstante las familias reconstituidas no se rigen por la misma lógica a la hora de la recomposición, siendo diferente aquella en la que la pareja de quien tiene la custodia reside con los hijos e hijas de ésta última y ocupa el lugar del progenitor que no convive con sus hijos o hijas (estaríamos ante una lógica de sustitución) y aquella otra en la que existe una negociación continuada

manzana envenenada) después de haber fallado su encargo al cazador. En esta versión la madrastra también muere.

26. También de padres y padrastros que, en algunos aspectos, estarían afectados por las cuestiones que mencionaré. Sin embargo voy a dejarlos a un lado para centrarme tan sólo en las figuras femeninas.

27. Yo no voy a tratarlo aquí pero entre madre y madrastra pueden existir otro tipo de tensiones de carácter personal o económico que no se derivan de modo directo de los hijos pero que puede afectarlos. Estas tensiones pueden transmitirse a otros miembros de la familia, por ejemplo a los abuelos y también provenir de otros miembros y situaciones, por ejemplo el padre de los hijos/as y su comportamiento en el primer matrimonio, el proceso de divorcio en sí y el grado de cumplimiento de sus deberes paternales posteriores. Puede verse al respecto: MONCó, Beatriz. «Códigos de interpretación de los acuerdos económicos del divorcio. El caso de las familias reconstituidas». Portularia X $\mathrm{n}^{\circ} 2$ (2010) pp. 1-8. 
entre quienes ya no son pareja y quienes lo son (lógica de la continuidad) ${ }^{28}$. Independientemente de lo que estos dos modos de reconstitución familiar supongan lo que está claro es que puede haber variaciones en la percepción de la madrastra si, por ejemplo, la madre no tiene la custodia y los hijos e hijas conviven desde pequeños con el padre y su pareja. En estos casos se podría elaborar un continuum en el que la madrastra se acerca o se aleja nominativa y sentimentalmente: unas veces y ante algunos es «mi madre», otras veces puede ser «la mujer de mi padre» y en otras el nombre propio vale para nombrarla, encontrando incluso variaciones importantes que pueden producirse por otras causas. El caso de Marisol es paradigmático en este aspecto. La primera mujer de su marido fue persona con ciertos trastornos de salud que dificultaron la convivencia con su hijo por lo que el niño pasaba grandes temporadas conviviendo con ella. Me explicaba emocionada: «cuando murió su madre [...] yo en mayo hago los años y me acuerdo que me compró una planta preciosa y dejó por ahí una tarjeta, que la tengo guardada, que decía: para mi segunda madre, ahora la primera». Sin embargo, cuando no hay convivencia, la figura de la madre desdibuja más a la madrastra y aun sin utilizar este término sí que el nombre propio, la posición de afinidad o incluso algunos términos cariñosos o, al contrario, despectivos si la relación es mala, hacen su aparición y toman protagonismo.

A lo largo de la entrevistas se aprecia también que los sentimientos y emociones de unos y otras son flexibles, abiertos, eclécticos, relacionados con la experiencia más que con una norma legal y cultural. Desde la perspectiva de las madrastras también la convivencia y la edad de los hijos e hijas del marido son claves. De hecho, algunas no hacen diferencias entre los hijos de la pareja y los propios y los llaman y tratan como hijos (sobre todo si desde pequeños conviven con ella), otras tienen claro que no son sus hijos desde un principio (si los conoce, por ejemplo, en la adolescencia y no conviven) y otras ven que la maternidad propia modifica en cierto modo la relación con los hijos de la pareja. En este último aspecto el caso de Francisca es muy significativo. Cuando la entrevisté tenía un hijo y esperaba otro; su marido tenía un niño de un matrimonio anterior al que ella había comenzado a tratar desde muy pequeño. A lo largo de la entrevista varias veces empleó el término «adorar»

28. LE GALL, Didier et MARTIN, Claude. «Transitions familiales, logiques de recompositions et modes de regulation conjugale» en MEURDERS-KLEIN, Marie Thérèse et THÉRY, Irène, Les recompositions familiales aujourd'hui. Paris, Nathan, 1993, pp. 137-158. Otros autores han realizado otras tipologías, pero a pesar de que obviamente la realidad es más rica que cualquier construcción tipológica, estas lógicas de Le Gall y Martin me parecen las más sencillas y claras, de ahí que las utilice. 
y sus derivados para explicar la relación que hay entre ellos, llegando incluso a comentar: «(el hijastro) siempre lo dice, yo tengo dos familias, yo tengo muchas suerte porque tengo dos familias. Tengo dos padres y dos madres». Sin embargo, cuando ella se visualiza como madre el discurso se matiza: «Yo creía que a M. (el hijastro) lo adoraba, y le sentí como un hijo mío, y te lo juro que siempre lo he pensado [...] hasta que tuve a V. (el primer hijo biológico). Y dices, jes que no se puede comparar, claro que no!» Los sentimientos fluctúan, las realidades familiares divergen y las personas ajustan sus comportamientos a las diversas circunstancias que la vida les plantea. Esto hace que las mujeres que son madrastras vayan adaptándose a situaciones diversas que se significan también de un modo distinto según determinadas variables pero también vemos que el modelo madre sigue ahí (recordemos a Marisol y Francisca), para aparecer cuando hace falta, para compararse, para explicar a los demás, para cumplir con sus objetivos de exclusividad.

Sin embargo si el hecho biológico, la custodia y la convivencia separan las figuras de madres y madrastras el cuidado las une. Aún debiendo tener en cuenta las variables ya mencionadas, las madrastras convivientes se ocupan del maternaje de un modo habitual ${ }^{29}$ (recordemos las palabras de Cecilia y Jorge), pero también lo hacen quienes no conviven regularmente con los hijos e hijas de la pareja cuando son de corta edad. Carlota, por ejemplo, le conoce desde que era pequeño. El niño vive con la abuela materna porque la madre lo abandonó. Comenta:

Yo le bañaba el fin de semana, y le preparaba la comida, pero entre semana no había nada. Yo le forraba los libros, iba a por los libros, pero porque la madre no estaba en ese momento, pero no porque yo tuviera oportunidad de ejercer el papel de madre [...] fue muy raro, fue una situación muy rara.

Efectivamente lleva razón Carlota: las confluencias de modelos culturales que se han construido como divergentes causa confusión en los actores sociales y el de madre y madrastra nacieron para vivir separados. O la nominación no cuadra con la experiencia, o ésta no encaja con las características de los modelos o las funciones son compartidas por personas representadas por construcciones culturales distintas, una es némesis de la otra. La madrastra cubrió históricamente un espacio que dejó vacío la ausencia de madre. Alguien que cuidara, una mujer que realizase los roles de maternaje que el modelo exigía a la madre, independientemente de que existiese o no cariño por los hijos de la pareja. Cabe aquí preguntarnos por qué la madrastra se construyó con

29. Evidentemente con las diferenciaciones propias de la situación económica, social y de corresponsabilidad y coparticipación del núcleo familiar. 
tan malos sentimientos y conductas y cabe también interrogarnos sobre la posibilidad de su distinción con la madre (más allá del hecho biológico) si el modelo no se hubiera construido negativamente. Dicho de otro modo: si naturalmente a las mujeres se nos suponen sentimientos maternales ipor qué quitárselos a la madrastra? Y si se dota de ellos a la madrastra y además convive y además realiza tareas de maternaje ¿no se confundirían ambos modelos? ¿Cómo mantener el orden social y simbólico en un escenario en el que algunos papeles nacidos para una total y absoluta singularidad no son únicos? $?^{30}$ Pensemos, además, que las madrastras son madres de sus hijos o hijas, al mismo tiempo e incluso en la misma casa. Sólo reforzando el modelo de maternidad, sólo teniendo presente el de madrastra (aunque no sea el caso concreto) podemos dejar de verlos como modelos anamórficos.

\section{Conclusión: heterodesignación y modelos femeninos}

Madres, madrastras y malas-madres; caras distintas en un juego de espejos invertidos que se necesitan y refuerzan mutuamente, que reflejan la realidad deformándola, achatándola, quitándole riqueza y pluralidad. El modelo de maternidad (y su contrario) se construyen sobre sentimientos, emociones y roles; uno y otro se valoran culturalmente y se juzgan moral y éticamente; uno y otro se interpretan partiendo de un vínculo natural entre la madre y el hijo o la hija; ambos, en definitiva, se hacen extensivos a toda mujer. Sin embargo, mientras las sociedades tienden a valorar la figura materna la mala madre queda en la sombra y sólo se define popularmente por incumplimiento de los preceptos del modelo cuando llega un caso en concreto. Una sombra en la que, como decía anteriormente, han hurgado moralistas, teólogos, pedagogos, psicólogos y filósofos para recordar una y otra vez la norma, para cambiar el peso específico de cada una de sus características, para configurar el bien del hijo, de su cuerpo y de su espíritu, dejando a la madre como mano de obra óptima para su educación, higiene y bienestar y, desde luego, como primera y única culpable si algo salía mal convirtiéndola en mala madre. Esta madre, que paradójicamente tiene un poder infinito sobre el niño a la vez que no tiene ninguno en el ámbito público (salvo que desde aquí se reflexione sobre el privado-doméstico), es guiada una y otra vez por la sabia mano de varios

30. Es significativo comparar estos modelos con el de madre biológica y madre adoptiva de una persona. Sólo en casos de conflictos muy graves se toma partido por una u otra. Pienso que el anonimato de la primera es clave para una normal coexistencia, aunque en casos concretos se pueda hablar de comaternidad. O comparemos con los casos en los que una mujer con hijos biológicos adopta un niño o una niña o los acoge. 
expertos y a través de contradictorias recetas ${ }^{31}$ que dificultan la total adscripción al modelo. El hijo, la madre, el hogar forman una perfecta triada que encauza el experto de turno. Aquello que se sale de lo impuesto, de lo heterodesignado por la sociedad patriarcal, corresponde a la mala madre o, en su caso, a la madrastra. Ambos términos negativos, insisto, sirven para reforzamiento del modelo de maternidad porque estamos ante un modelo exclusivo, único, que no admite réplica ni puede tener coexistencia con ningún otro.

Este modelo unido de un modo que parecía indisoluble a la familia nuclear en occidente se vio puesto en cuestión con las familias recompuestas en tanto daban entrada a una persona que podía sustituir a la madre, coexistir simplemente o entrar en comparación o competencia, después. La solución vino primero de la mano del modelo hipernegativo de madrastra, después con un nuevo reforzamiento del materno en materia de maternaje que le hizo permanecer inalterable e inalterado en cualquier modelo de familia ${ }^{32}$. Frente a la madrastra no hay malas madres ${ }^{33}$, significa el modelo de continuo si se cumple con los mandatos del mismo. Sólo quienes abandonan a sus hijos e hijas, quienes los maltratan, quienes no se sacrifican por su cuidado son malas madres e incluso de éstas se puede argüir para reforzamiento del modelo maternal que o «no son madres de verdad» (¿qué podrían ser entonces?, me pregunto) o están enfermas. ¿Pero qué ocurre cuando se cumple el modelo y el sacrificio, el cuidado y la protección resultan dañinos? Necesitaría más espacio para transcribir parte de las entrevistas en las que diferentes personas me han hablado de madres castradoras, egoístas, absorbentes y chantajistas. Necesitaría también más espacio para transmitir la información de quienes hablaban de madres enriquecedoras, entrañables, cariñosas y bondadosas. No depende, por tanto del tipo familiar. Es una cuestión personal, de límites, evidentemente, pero también social y cultural. La maternidad (la buena y la mala) e incluso la que puede en cierta forma representar una madrastra no es sólo algo individual es un hacer colectivo en el que, como decía con anterioridad, se busca al enemigo fuera cuando en realidad está dentro. Independientemente de la experiencia real de cada cual, el de maternidad es un modelo que puede engañar, coartar, desajustar y herir tanto al hijo o hija como a la

31. Véase al respecto EhrenReich, Barbara y ENGLISH, Deirdre. Por su propio bien. 150 años de consejos de expertos a las mujeres. Madrid, Taurus, 1990.

32. En el caso de las transnacionales la separación de la madre de las tareas de la crianza se interpretan sólo como un déficit y la familia en sí como algo novedoso cuando, de nuevo, es un tipo rastreable en la historia que, en realidad, puede verse desde perspectivas más abiertas.

33. «Más vale una mala madre que una buena madrastra», dice el refrán popular.

Feminismo/s 23, junio 2014, pp. 113-133 
madre si no están alertas uno y otras ${ }^{34}$. No es de extrañar que el feminismo radical proclamase a gritos su matrofobia, no lo es sin duda que entre tanto falso poder otorgado por un modelo patriarcal se quieran recuperar genealogías y órdenes simbólicos maternos, pero tampoco lo es que el feminismo de la igualdad grite que con esas madres, preferible ser huérfanas ${ }^{35}$. El feminismo, tan crítico con la obligación patriarcal y maternal de la familia tradicional y con esta misma, no lo ha sido tanto con el derecho a la maternidad y el poder personal y/o simbólico que concede. Ser madre se ha convertido en un derecho ¿para cuándo el derecho a no serlo?

Por otra parte, e independientemente de que sea en pareja o en solitario, con persona de igual o diferentes sexo, el poder social de la madre queda en modelo y discurso, traduciéndose en poder sobre el hijo o la hija, sobre su vida y su persona con el beneplácito de una sociedad que apoya este modelo fagocitador, tóxico donde los haya, cerrando los ojos, oídos y boca hacia los desmanes de unas y los requerimientos del otro. La madre omnívora vive una vida que no le corresponde, que es de otra persona, mientras que el hijo o la hija, instalados en el modelo de sacrificio materno, pueden lastrar continuamente la existencia de la mujer que es madre por querer hablar con voz propia, por abrir sus alas y volar con autonomía e independencia, sin más culpas, sin más extravíos, sin más explicaciones.

Por otra parte, los movimientos feministas (como amplio abanico de teoría crítica que son) no han podido modificar este modelo sino tan sólo su interpretación y valoración. Como he expuesto al principio, las diversas opiniones han ido marcando un ritmo de acción- reacción que nos han llevado al resurgimiento de unas maternidades que creíamos ya pretéritas y que ahora vienen disfrazadas de modernidad ${ }^{36}$ pero que en mi opinión representan una involución para las mujeres. En familias nucleares, reconstituidas, transnacionales o monomarentales; siendo madres biológicas o sólo sociales, sea cual sea nuestra orientación sexual, la sociedad patriarcal heterodesigna a las mujeres

34. Es necesario recordar, sin embargo, que el modelo permite, por normativa genérica, ciertas diferencias según hablemos de hija o hijo.

35. Muraro, Luisa. El orden simbólico de la madre. Madrid, Horas y Horas, 1994 y como contrapunto CiRillo, Lydia. Mejor huérfanas. Por una crítica feminista al pensamiento de la diferencia.Barcelona, Anthropos, 2002. (Los originales italianos de ambos textos son de 1991 y 1993)

36. Me refiero a las ideas y conductas exigidas por la teoría del apego, la teoría del vínculo, el colecho, la crianza natural y a demanda, etc. y al hecho de la revalorización del instinto maternal. Llamo la atención también hacia la denominada «opt-out generation» una generación de mujeres educadas en las mejores universidades norteamericanas (especialmente), con trabajos de éxito y excelentes remuneraciones que abandonan el escenario público para dedicarse al completo al cuidado de los hijos e hijas. 
por igual: somos madres, somos las cuidadoras de la especie. Ya sea mediante procesos de naturalización, ya sea mediante modelos que abren requerimientos que parecían haberse cerrado, el encuentro de las mujeres con la maternidad ni ha sido ni es pacífico. Dobles presencias, conciliaciones difíciles, contradicciones entre los deberes de madre y trabajadora, paradojas entre Políticas Públicas y necesidades reales son sólo parte del ejercicio de ser mujer y madre actualmente ${ }^{37}$. Ha cambiado nuestra vida, se han multiplicado nuestros roles, tenemos autoexigencias y deseos personales que queremos cumplir, se han transformado estructuralmente nuestras familias y sin embargo el modelo dominante de maternidad ha permanecido inalterable desde hace siglos, para lo bueno y para lo malo, para sus prebendas y sus sacrificios. Antes hablábamos del poder de la madre, ahora del empoderamiento que da el ser madre. Antes íbamos de la mano de nuestras parejas, ahora solas (ies actualmente el deseo del hijo más libre por hacerlo en solitario o debemos pensar que la sombra del patriarcado es alargada?) o con parejas del mismo sexo. Hablamos de nuevas madres y de nuevas familias pero el modelo sigue hablando de viejas maternidades y viejas exigencias. Requerimientos que siguen culpabilizándonos y agotándonos y que sólo abandonaremos construyendo nuevos escenarios familiares. Escenarios familiares que no son «nuevas familias». Es hora de ir abandonando estos términos que diferencian y sólo sirven para hacer tipologías y singularizaciones exclusivas y excluyentes o reformulaciones de lo ya antiguo ${ }^{38}$ y hablar de familias, sin más, como concepto plural significativo de grupos humanos en donde niños y niñas puedan desarrollarse y crecer en las mejores condiciones posibles con padre y madre, con padre y madrastra, con madre y padrastro, sólo con madre, sólo con padre, con dos padres y con dos madres o sin ninguna de estas figuras. Escenarios familiares

37. No es nuevo el análisis de las paradojas que surgen en la interacción del modelo y la realidad. Puede verse HAYS, Sharon. Las contradicciones culturales de la maternidad. Barcelona, Paidós, 1998.

38. La variabilidad de casos que encuadra la tradicionalmente llamada monoparentalidad significativa, además, de formas familiares distintas o el hecho de que actualmente en el colectivo de las denominadas madres solteras por elección (monoparentales, desde otro punto de vista) se incluyan tanto las de proyecto previo de maternidad (por adopción o TRA) como las mujeres con pareja que una vez embarazadas quedaron solas y decidieron continuar hasta el nacimiento de su hija o hija, creo que dan muestra de lo que digo. Obviamente se puede hablar de «nuevas familias» como modelos emergentes, tal y como lo hace IMAZ, Elixabete. «La maternidad en el seno de las parejas lesbianas: cambios continuidades y rupturas respecto a los modelos familiares y maternales», Arxius de sociología, 15 (2006) pp. 89-100, aunque considero preferible la conceptualización general. 
igualitarios ${ }^{39}$, solidarios ${ }^{40}$ participativos, con corresponsabilidad de todos sus miembros, también hijos e hijas, en los que los modelos de género se hayan deconstruido y en los que el modelo maternal y el cuidado no sean un lastre para nadie. Necesitamos esos escenarios familiares pero sobre todo nuevos modos de ser hombres y mujeres y quizás de ser padres y madres.

\section{Referencias bibliográficas}

AlBERDI, Inés. «La transformación de las familias en España. La influencia del feminismo en los cambios familiares». Arxius de Sociología 15 (2006), pp. $25-40$

AYUSO, Luis. «Living apart together en España ¿Noviazgos o parejas independientes?». Revista Internacional de Sociología 70, 3 (2012), pp.587-613

BADINTER, Elisabeth. ¿Existe el amor maternal? Historia del amor maternal. Siglos XVII al XX. Barcelona, Paidós, 1991.

- Por el mal camino. Madrid, Alianza Editorial, 2004.

- La mujer y la madre. Madrid, La esfera de los libros, 2011.

Bauman, Zygmunt. Amor líquido. Acerca de la fragilidad de los vínculos humanos. Madrid, FCE, 2005.

BECK, Ulrich y BECK-GERNSHEIM, Elisabeth. La individualización. El individualismo institucionalizado y sus consecuencias sociales y políticas. Barcelona, Paidós, 2003.

BEAUvoIR, Simone de. Une morte très douce. Paris, Gallimard, 1964.

Bourdieu, Pierre. «Des familles sans nom». Actes de la Recherche en Sciences Sociales 13, $\mathrm{n}^{\circ} 1$ (1996), pp. 3-5.

CID LÓPEZ, Rosa María (ed.). Maternidad/es: representaciones y realidad social. Edades antigua y media. Madrid, Al-Mudayna, 2010.

Cirillo, Lydia. Mejor huérfanas. Por una crítica feminista al pensamiento de la diferencia. Barcelona, Anthropos, 2002.

CHODOROW, Nancy. El ejercicio de la maternidad. Barcelona, Gedisa, 1984.

EhrenReich, Barbara y ENGLiSH, Deirdre. Por su propio bien. 150 años de consejos de expertos a las mujeres. Madrid, Taurus, 1990.

FiRESTONE, Shulamith. La dialéctica del sexo. Barcelona, Kairós, 1976.

FLANDRIN, Jean Louis. Orígenes de la familia moderna. La familia, el parentesco y la sexualidad en la sociedad tradicional. Barcelona, Crítica, 1979.

39. HAKIM, Catherine. Modelos de familia en las sociedades modernas. Ideales y realidades. CIS, Madrid, 2003

40. Knijn, Trudie y Komter, Aalke (Eds.). Solidarity between the sexes and the generation. Transformations in Europe. Edward Elgar Publishing, Cheltenham, 2004 
FRANCO RUBIO, Gloria A. (ed.). Debates sobre maternidades desde una perspectiva histórica. Siglos XVI-XX. Barcelona, Icaria Editorial, 2010.

HAKIM, Catherine. Modelos de familia en las sociedades modernas. Ideales y realidades. Madrid, CIS, 2003.

HAYs, Sharon. Las contradicciones culturales de la maternidad. Barcelona, Paidós, 1998.

IMAZ, Elixabete. «La maternidad en el seno de las parejas lesbianas: cambios, continuidades y rupturas respecto a los modelos familiares y maternales». Arxius de sociología 15 (2006), pp. 89-100.

- Convertirse en madre. Etnografía de la gestación. Madrid, Cátedra, 2010.

KNIBIELHER, Yvonne. Historia de las madres y de la maternidad en occidente. Buenos Aires, Nueva Visión, 2001.

KNIJN, Trudie y KOMPER, Aalke (eds.). Solidarity between the sexes and the generation: Transformations in Europe. Cheltenham, Edward Elgar Publishing, 2004

LA COMTESSE DE SÉGUR. Les petites filles modèles. Paris, Hachette, 1930.

LE GALL, Didier y MARTIN, Claude. «Transitions familiales, logiques de recompositions et modes de regulation conjugale», en MEURDERS-KLEIN, Marie Thérèse y THÉRY, Irène: Les recompositions familiales aujourd'hui, Paris, Nathan, 1993, pp. 137-158.

Martín Casares, Aurelia. Antropología del género. Cultura, mitos y estereotipos sexuales. Madrid, Cátedra, 2006.

MÉndEZ, Lourdes. Antropología feminista. Madrid, Editorial Síntesis, 2007.

Moncó, Beatriz. Mercedes quiere ser bombera. Barcelona, Bellaterra, 2004.

- Los hombres no pegan. Barcelona. Bellaterra, 2005.

- Clara y la ciudadanía. Barcelona. Bellaterra, 2009.

- «Códigos de interpretación de los acuerdos económicos del divorcio. El caso de las familias reconstituidas». Portularia X, no 2 (2010), pp. 1-8.

- Antropología del género. Madrid, Editorial Síntesis, 2011.

Moncó, Beatriz y RIVAS, Ana María. «La importancia de nombrar. El uso de la terminología de parentesco en las familias reconstituidas» Gazeta de antropología (2007). Artículo 23, revista electrónica.

MurARO, Luisa. El orden simbólico de la madre. Madrid, Horas y Horas, 1994.

Rich, Adrianne. Nacemos de Mujer. La maternidad como experiencia e institución. Madrid, Cátedra, 1996.

THÉRY, Irène. «Remariage et familles composées: des evidences aux incertitudes». L'Année Sociologique, 37 (1987), pp. 119-152.

TOUPIN, Louise. «Des usages de la maternitè en histoire du feminisme». Recherches feministes, $9 \mathrm{n}^{\circ} 2$ (1996), pp. 113-135. 